\title{
INFORME SOBRE LOS RESTOS DE FAUNA RECUPERADOS EN EL CORTE E (1983-1985) DE LA PEÑA NEGRA (CREVILLENTE, ALICANTE)*
}

\author{
ADOLFO AGUILAR \\ ARTURO MORALES \\ RUTH MORENO \\ Laboratorio de Zooarqueología \\ Universidad Autónoma de Madrid
}

\begin{abstract}
Se ofrece un análisis de los restos óseos recuperados en el yacimiento del Bronce Final de La Peña Negra (Crevillente, Alicante). El material estudiado consiste en una muestra preseleccionada por el excavador, lo que explica la ausencia de especímenes inidentificables, la anormal abundancia de huesos completos y la inexistencia de restos por debajo de una talla crítica. Ello obliga a ser cautos a la hora de valorar la fuente de subsistencia de estas gentes: bóvidos u ovinos. Las hipótesis formuladas en este trabajo deberán ser contrastadas con los resultados del análisis de la totalidad de la fauna del mismo nivel.

The faunal analysis carried out on a previously selected sample from the assemblage recovered in Peña Negra (Late Bronce Age, Prov. Alicante) highlights all the weaknesses of a partial recovery of remains. Absence of unidintefied specimens, abnormal abundance of complete bones and absence of bones below a critical size are evident in the sample studied. All of them force us to be suspicious as to the interpretation of the fauna which seems, nevertheless, dominated by domestic species, though, at the moment, (for the reasons given) we are unable to decide wether bovine or ovine husbandry was most important for the people at the site.

The series of hypothesis which have been advanced in the present work will have to be substantiated through further research on the remaining fraction of this faunal assemblage. Rejection or adoption of these can only come through empirical testing with more reliable data than the ones presented here.
\end{abstract}




\section{PRIMERA PARTE: COMENTARIOS DE ÍNDOLE METODOLÓGICA}

\section{INTRODUCCIÓN}

En el presente informe se hace una primera valoración de la fauna recuperada en el yacimiento alicantino de Peña Negra, del Bronce Final. En ella, además de proporcionar la información clásica de todo informe faunístico (en este caso muy sucintamente) discutimos la naturaleza y significado de la muestra desde una perspectiva no sólo paleocultural, sino también tafonómica y estadística.

El yacimiento de Peña Negra fue excavado bajo la dirección de D. Alfredo González Prats. Los restos de las faunas, osamentas en su mayoría, en su

* Nota de A. González Prats. Este trabajo fue entregado en 1989 y constituía uno de los apéndices de la Memoria de excavaciones de 1983-85. Dado el coste de edición de aquella nos vimos obligados a retirar tres de los cuatro apéndices que la acompañaban, por eso hemos optado por darlo a conocer en este número de Lucentum.

Como se indica en el informe, el director de las excavaciones procedió a enviar para su análisis al Laboratorio de Zooarqueología de la U.A.M. el material osteológico susceptible de identificación a excepción del volumen de esquirlas y huesos astillados sin presencia de epífisis alguna y por muy pequeño que fuera: no se seleccionó sólo las piezas más grandes o más completas. Sí que se eliminó, en cambio, la fracción SI. Una remesa paralela que contenía el volumen total de los huesos-incluyendo el amplio grupo SI-fue enviado a la Universidad de Murcia, en donde el Prof. Morales impartía junto con el Prof. Walker, un curso de doctorado. El informe resultante no ha sido remitido todavía e ignoro las causas de tal retraso.

En un reciente artículo (Archaeofauna 1,1992) basado en los análisis que aquí se presentan, A. Morales y R. Moreno utilizan la selección realizada por el director de las excavaciones para ejemplarizar un caso de distorsión de Indole cultural con el que me encuentro totalmente de acuerdo. Sin embargo, he de advertir dos graves errores motivados seguramente por la falta de comunicación pertinente que se vierten en dicho articulo. Por un lado, no es correcto que en el Corte $\mathrm{E}$ los niveles I y 11 pertenezcan al mismo período del Bronce Final (MORALES-MORENO, 1992, 2), como tampoco se ajusta a la realidad la afirmación que existió «recuperación parcial (de visu) durante la excavación» (Ibidem, 7). Esta dirección de excavaciones tiene por principio la recogida sistemática de todo tipo de material susceptible de estudio, entre el que la fauna constituye un elemento sustancial. De nuevo se ha confundido la preselección de los restos en el laboratorio para su envío, como se comenta arriba, con otro tipo de «preselección» directamente en la excavación. Toda la sedimentación arqueológica del Corte E pasó por cribas, eso sí, con una red de $3 \mathrm{~mm}$. de luz, lo que sin duda posibilitó la pérdida de gran parte de la posible microfauna. mayoría por lo que puede desprenderse de este análisis, pero también conchas, son mucho más abundantes de lo que cabría deducir de una lectura precipitada del análisis. Sucede, sin embargo, que el Profesor González Prats consideró más adecuado para nuestra labor tan sólo aquellas piezas completas o en donde la fragmentación hubiese resultado menos acusada. (GONZÁLEZ PRATS, com. verb.). Al hacer esto se introduce involuntariamente un sesgo de tipo «cultural» (s.l.) en el sentido de favorecer a determinadas especies (macromamíferos) e individuos adultos, machos, etc., con huesos más grandes o duraderos. Este sesgo afectaría también a aquellas piezas que por su mayor grado de mineralización resultasen menos afectadas y fragmentadas por los distintos factores tafonómicos que hayan operado sobre el conjunto de la muestra. En esta situación podrían encontrarse, por ej., las piezas dentarias. Todo esto, por tanto, debería traducirse a unas falsas imágenes de abundancia taxonómica y representatividad esquelética, al menos según los cánones establecidos (PAYNE, 1972).

Sin embargo, y como quiera que el resto de la fauna permanece aún disponible para su estudio, nos encontramos, por azares del destino, en una situación óptima para analizar y contestar todos estos fenómenos que tantos ríos de tinta han hecho correr a los metodólogos de la zooarqueología. De ahí la necesidad de publicar este informe antes de los demás. En estos momentos carecemos de datos acerca de la naturaleza del resto de la fauna de Peña Negra, recuperada pero no enviada a estudio.

Los signos y las siglas son los habituales, para aclaraciones ver (MORALES, 1977; MIGUELMORALES, 1983).

\section{RESULTADOS}

En las tablas 1-3 quedan reflejados los principales resultados del análisis (especies, abundancias específicas en cuanto a NR y NMI así como desglose anatómico de restos por especies). Las relaciones pormenorizadas de edades, restos y medidas serán objeto de un apartado posterior.

Además de los 416 restos de mamíferos en el corte E de Peña Negra se recuperaron restos de ave (un radio de una paseriforme del tamaño de un córvido) y de moluscos que se distribuyen como sigue: 


\begin{tabular}{lrrr}
\hline Especie & Nivel 1 & Nivel II & Total \\
\hline Strombus latus & - & $(1)$ & $1(1)$ \\
Glycimeris glycimeris & $3(2)$ & $1(1)$ & $4(3)$ \\
Acanthocardia tuberculata & $2(2)$ & $-2(2)$ & $-2(2$ \\
Spondylus gaederopus & $2(2)$ & $1(1)$ & $3(3)$ \\
TOTAL & $7(6)$ & $3(3)$ & $10(9)$ \\
\hline
\end{tabular}

Los números entre paréntesis se refieren al NMI que se corresponde con el NR. El estudio de los moluscos se hará posteriormente y de modo independiente en otro trabajo.

Como comentario general podemos decir que se trata de un tipo de asociación faunística clásica en un yacimiento arqueológico, con especies domésticas dominado tanto por NR $(74,7 \%)$ como NMI $(64,7 \%)$. No queda claro si el conejo puede ser doméstico o silvestre, o si la muestra de esta especie en el yacimiento podría incluir ambos tipos de poblaciones. Aunque por estas fechas se postuló la domesticación del conejo en la Península (von den Driesch, 1972), tal hipótesis descansa sobre una base, cuando menos, menguada de restos. Por todo ello creemos más adecuado pensar que los conejos de Peña Negra procedían de ejemplares silvestres. En caso contrario, la dominancia de la fauna doméstica sería abrumadora $(90,8 \%$ del NR y $78,4 \%$ del NMI).

Aunque existen algunas pequeñas esquirlas sin identificar entre la muestra, todas presentan fracturaciones recientes, posiblemente incluso durante el transporte de los restos al laboratorio. Tratándose por tanto de porciones de huesos identificados consideramos más conveniente no volver a contabilizarlos como restos «independientes». De este modo, la fracción $\mathrm{SI}=0$.

\section{DISCUSIÓN}

Un análisis detallado de las tablas 1-3 nos pone de manifiesto una serie de puntos. Algunos de estos son merecedores de comentarios adicionales.

En primer lugar, y por lo que acabamos de decir, un dato llamativo de esta muestra es la ausencia de fragmentos SI. En casi todas las muestras zooarqueológicas estudiadas, no sólo en España, sino de todo el mundo; la fracción SI suele ser apreciable, llegando incluso a superar por NR a la fracción identificada del total de restos. Morales (1987) habla de valores óptimos de identificabilidad en muestras cuando su índice de recuperación presenta valores óptimos próximos a 10.
En esta situación teórica tendríamos 100 restos identificados por cada resto sin identificar. Más realista sería pensar en situaciones en donde el índice arrojase valores de 100 (10 identificados por cada no identificado). Incluso en numerosos yacimientos los valores se invierten y la fracción SI puede llegar a ser hasta 100 veces más frecuente que la de restos identificados (p. ej. en cremaciones, tumbas, etc.). Sea como fuera, lo cierto es que la situación detectada en Peña Negra puede calificarse ciertamente de anómala. De ella podemos derivar la primera conclusión del informe: la composición cualitativa de la fauna total probablemente no cambie demasiado en lo que se refiere a macro- y mesomamíferos. Sin embargo, la ausencia de restos SI en la muestra habla de una selectividad dentro de la submuestra sometida a estudio que muy posiblemente produzca cambios cuantitativos significativos en la composición y abundancia taxonómica. Por eso, cualquier conclusión que se extraiga aquí sobre la diversidad deberá ser tomada tentativamente y a modo de aproximación.

Pasando a continuación a examinar la representatividad esquelética por taxones, observamos también detalles dignos de comentario. Para empezar podemos apreciar dentro de las tres muestras con mayores efectivos numéricos (bovino, «ovicaprino» y conejos) situaciones bien distintas que producen 2-3 patrones de representatividad característica. (Gráficos 3-5). De este modo los mamíferos domésticos se caracterizan por una pobrísima representación del esqueleto axial (alrededor del $2 \%$ del total) que contrasta con los altos valores del conejo (casi el $20 \%$ del total), diez veces mayor en términos relativos que la de los Ungulados. $\mathrm{Al}$ mismo tiempo, el esqueleto craneal de los bóvidos presenta valores entre 40-60\% del total de las respectivas muestras, mientras que en el conejo estos mismos valores no alcanzan el $15 \%$ del total. Los contrastes entre las fracciones apendiculares de las tres muestras no son tan acusados: el $65 \%$ que esta fracción representa en el conejo es bastante parecida al valor de la misma en el vacuno (casi el 54\%), aunque casi duplica a la de los ovicaprinos en conjunto (36\%). Para concluir esta panorámica general hay que destacar que las muestras de los mamíferos domésticos, mayores en cuanto a NR que la del conejo, reparten también sus efectivos sobre un mayor número de huesos que en el lagomorfo. Esto obliga a un análisis más detallado de los patrones de representatividad del que supone un simple desglose esquelético en «craneal-axial-apendicular». 
En este análisis detallado un dato emerge claro independientemente del patrón global de representatividad: las piezas completas son las principales responsables de las distribuciones observadas, independientemente de sus tamaños. En el vacuno los valores más altos corresponden a dientes inferiores $(18,5 \%)$, falanges $(17,5 \%)$, tarsales $(13,4 \%)$ y dientes superiores $(12,4 \%)$, piezas todas ellas que en la muestra de Peña Negra (y en yacimientos arqueológicos en general) se encuentran completas. Igual ocurre en ovicaprinos, donde además de dientes superiores $(28,5 \%)$, inferiores (14\%) y mandíbulas $(14,3 \%)$ las únicas piezas que son realmente abundantes son las tarsales (12\%). Aunque las mandíbulas de ovicaprinos suelen aparecer rotas por la sínfisis, su morfología continúa siendo muy característica. Es significativo comprobar cómo este patrón se mantiene, a pesar de las evidentes diferencias de tamaño, en la muestra del conejo. Aquí son las vértebras (casi todas lumbares y todas completas) y las pelvis (mejor dicho, hemipelvis) las piezas que aparecen con mayor frecuencia (19\%), seguidas del húmero (15\%) y de escápulas y mandíbulas (10\%), completas en un gran porcentaje de los casos.

Las piezas por debajo de una talla crítica no aparecen representadas en ninguna de las muestras. Así por ejemplo los sesamoideos sólo aparecen en las especies de mayor tamaño (caballo y vacuno), las falanges sólo faltan en el cerdo y el conejo y en esta última especie todas las piezas ausentes de la muestra (carpales, tarsales, metacarpos, metatarsos, dientes sueltos...) son, curiosamente, aquellas de menor tamaño (para más detalle de esta representatividad en función de la talla examinar cuidadosamente las diferentes categorías representadas en la tabla 4). Claramente nos encontramos ante un factor de distorsión que debemos achacar a la selección previa de los restos.

Como corolario, y hasta cierto punto corroboración del anterior fenómeno, podemos comprobar cómo el grado de fragmentación (factor que tiene también una incidencia directa sobre las tallas) incide negativamente sobre la representatividad esquelética. Las mandíbulas de conejo $(10,4 \%)$ y de ovicaprinos (14\%), apenas fragmentadas, presentan valores muy superiores en su representatividad a los del vacuno $(6 \%)$ en donde, pese al tamaño muy superior de sus quijadas, éstas aparecen siempre (salvo una hemimandíbula D) bastante o muy fragmentadas. Ejemplos de este tipo podríamos repetir para casi cualquier hueso del esqueleto apendicular. En los

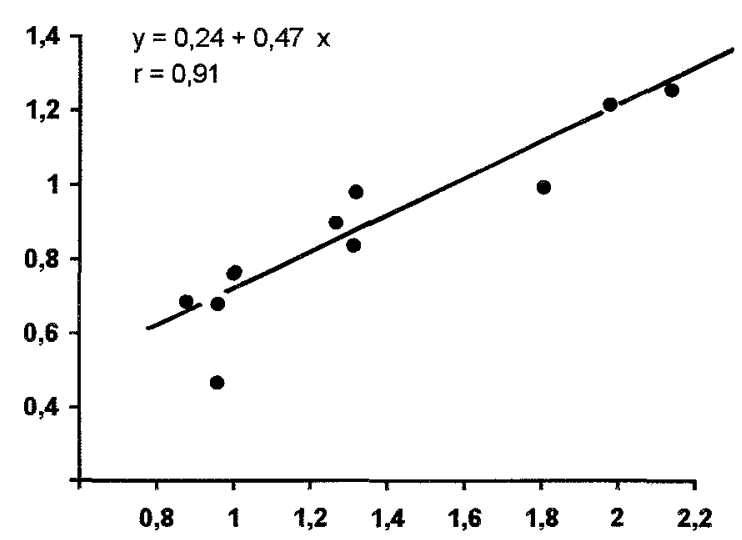

Gráfico 1.- La relación entre el $\log$ NR (abscisas) y el $\log$ del $n .{ }^{\circ}$ de categorías esqueléticas presentes en cada taxón (NCE, ordenadas) sigue una estrecha correlación lineal positiva. Esto significa que la selección previa del material analizado en este informe posiblemente afecte a todos los taxones de igual modo. Por lo mismo, tenemos razones para pensar que, aunque cuantitativamente la muestra haya sido distorsionada, los resultados cualitativos del análisis continúan siendo válidos.

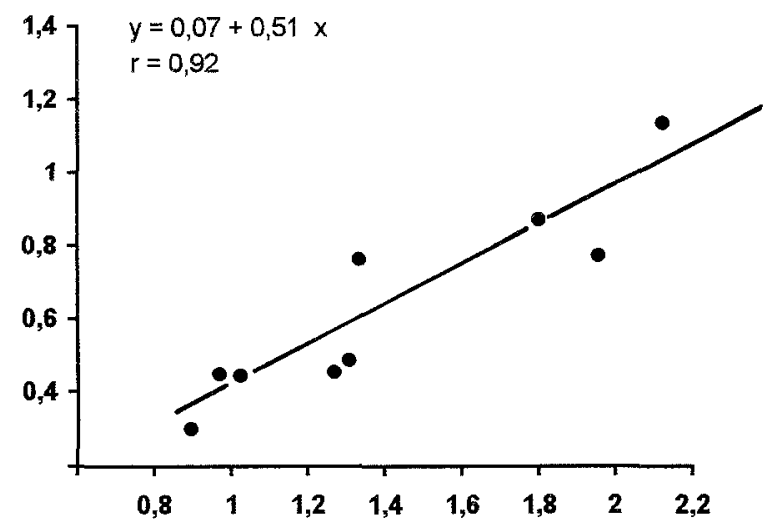

Gráfico 2.- Los efectos distorsionantes de la selección previa de la muestra quedan patentes al representar los $\log$ de NR (abscisas) y NMI (ordenadas). Así, aunque continúa siendo patente una correlación positiva entre ambos parámetros, observamos cómo con NR bastante diferentes les corresponden iguales NMl (GRAYSON, 1984).

gráficos 3-5 vemos cómo esta fracción esquelética suele presentar bajos porcentajes en todos aquellos huesos que se encuentran fracturados (húmero, radio, ulna, fémur, tibia) y porcentajes altos en los que aparecen completos (tarsos, falanges). Evidentemente, se debe tratar de algo más que de una casualidad.

Creemos que con todo esto queda suficientemente clara la distorsión introducida en la muestra faunística por la selección previa de restos ¿podemos pensar 


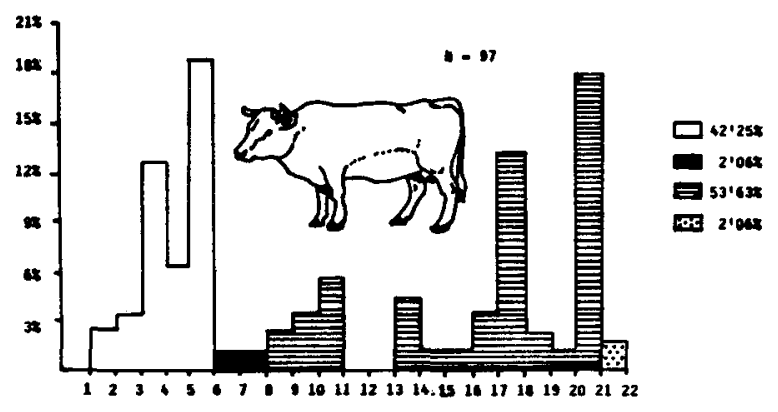

Gráfico 3.- Representación gráfica del desglose porcentual de los restos de vacuno según porciones esqueléticas (blanco= craneal; negro $=$ axial $;$ rayado $=$ apendicular; punteado $=$ varios $)$.

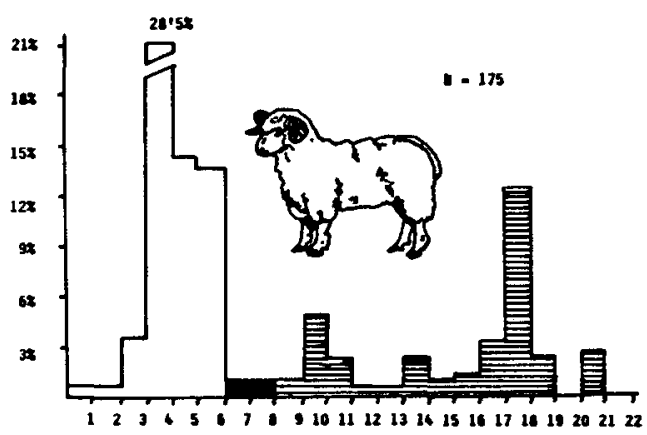

Gráfico 4.- Representación gráfica del desglose porcentual de los restos de ovicaprinos según porciones esqueléticas. Ver Gráfico 3 para explicación del sombreado.
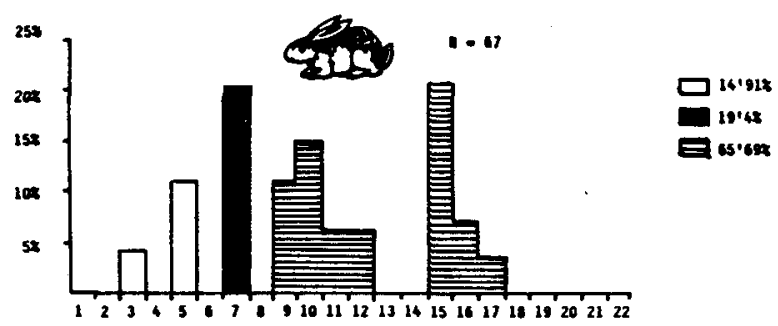

Gráfico 5.- Representación gráfica del desglose porcentual de los restos de conejo según porciones esqueléticas. Ver Gráfico 3 para explicación del sombreado.

que, a pesar de todo, es posible establecer algunas conclusiones de naturaleza paleocultural?: difícilmente. La distorsión que aquí sólo comentamos para huesos y especies debe ser general y afectar a todas las variables de las poblaciones animales (cohortes de edad, estructura sexual, etc.). Por esta razón, cualquier conclusión podría ser errónea y originar malas interpretaciones. Tomemos un ejemplo: la ausencia de vértebras y de costillas en las cabañas de mamíferos domésticos por una parte y la abundancia de piezas con escaso valor cárnico (dientes, falanges, tarsos) podría tomarse como indicativo de que estas poblaciones no se aprovechaban con fines alimenticios, ¿puede alguien creer ésto? Posiblemente, las vértebras y las costillas, fragmentadas, se encuentran con el resto de la fauna aún no estudiada. Debemos esperar el análisis de esta porción de la fauna para poder conjeturar con cierto grado de fiabilidad nuestras conclusiones. Hasta entonces concluiremos que hemos sido capaces de plantear una serie de hipótesis sobre la base de los datos aportados por el estudio de esta primera remesa de material y que ahora nos encontramos en una situación óptima para confirmar o refutar nuestros postulados.

\begin{tabular}{lrrrr}
\hline Especie & NR & $\%$ & NMI & $\%$ \\
\hline Caballo & 20 & 4,80 & 3 & 5,88 \\
Vaca & 97 & 23,31 & 7 & 13,72 \\
Oveja & 9 & 2,16 & 3 & 5,88 \\
Ovicaprinos & 157 & 37,74 & 14 & 27,45 \\
Cabra & 9 & 2,16 & 3 & 5,88 \\
Cerdo & 19 & 4,56 & 3 & 5,88 \\
Cabra Montés & 7 & 1,68 & 2 & 3,92 \\
Ciervo & 21 & 5,04 & 6 & 11,76 \\
Corzo & 10 & 2,40 & 3 & 5,88 \\
Conejo & 67 & 16,10 & 7 & 13,72 \\
TOTAL & 416 & 100,00 & 51 & 100,00 \\
\hline
\end{tabular}

Tabla 1.- Relación general de restos (NR) e individuos (NMI) de mamíferos recuperados en el corte «E».

\section{CONCLUSIONES}

Resulta chocante concluir un informe de fauna sin llegar a unas mínimas conclusiones. Las nuestras son más de carácter metodológico que estrictamente zoológico, paleocultural o biológico.

$\mathrm{El}$ análisis de una fauna preseleccionada para su estudio, como ha sido esta de Peña Negra, demuestra algunas de las limitaciones que dicha actividad puede introducir en zooarqueología. La ausencia de fragmentos sin identificar, la abundancia de piezas completas y la ausencia de huesos por debajo de una talla crítica contribuyen a generar una falsa imagen de manipulación de los huesos así como de la abundancia taxonómica y esquelética. Todo ello nos obliga a ser 


\begin{tabular}{|c|c|c|c|c|c|c|c|c|}
\hline Porción esquelética & Caballo & Vaca & Ovicáp. & Cerdo & Ciervo & Corzo & Conejo & Total \\
\hline Neurocráneo & - & 2 & - & - & - & - & - & 2 \\
\hline Viscerocráneo & - & 1 & 2 & - & - & - & - & 3 \\
\hline Dientes superiores & - & 3 & 12 & - & - & 1 & - & 16 \\
\hline Dientes inferiores & 1 & 1 & 11 & - & - & - & - & 13 \\
\hline Vértebras & - & - & - & - & 1 & - & - & 1 \\
\hline Escápula & - & - & - & 4 & - & 1 & - & 5 \\
\hline Húmero & - & 2 & - & - & - & - & - & 2 \\
\hline Radio & - & 1 & 2 & - & - & - & 1 & 2 \\
\hline Carpales & - & - & 1 & - & - & - & - & 1 \\
\hline Metacarpo & - & 1 & 1 & - & - & - & - & 2 \\
\hline Pelvis & 1 & - & - & - & - & - & 2 & 3 \\
\hline Tibia & 1 & - & - & - & - & - & 2 & 3 \\
\hline Tarsales & - & 3 & 1 & - & 2 & - & - & 6 \\
\hline Metatarso & - & 1 & - & - & - & - & - & 1 \\
\hline Falanges & - & 4 & - & - & - & - & - & 4 \\
\hline TOTAL & 2 & 19 & 29 & 5 & 3 & 2 & 3 & 63 \\
\hline
\end{tabular}

Tabla 2.- Desglose del NR mamaliano en el Nivel I por porciones esqueléticas.

\begin{tabular}{|c|c|c|c|c|c|c|c|c|c|c|c|}
\hline Porción esquelética & Caballo & Vaca & Oveja & $\mathrm{O} / \mathrm{C}$ & Cabra & Cerdo & Ciervo & Corzo & C. Mont & Conejo & Total \\
\hline Asta/Cuerno & - & - & - & - & 1 & - & 1 & - & - & - & 2 \\
\hline Neurocráneo & - & - & - & 1 & - & - & - & - & 1 & - & 2 \\
\hline Viscerocráneo & - & 2 & - & 4 & - & 2 & - & 1 & - & 3 & 12 \\
\hline Dientes superiores & 3 & 9 & - & 38 & - & - & - & - & - & - & 50 \\
\hline Dientes inferiores & 3 & 17 & - & 13 & - & 7 & 7 & 4 & - & - & 51 \\
\hline Mandíbula & - & 6 & - & 25 & - & - & 3 & 2 & - & 7 & 43 \\
\hline Vértebras & - & 1 & - & 2 & - & 1 & 1 & - & 1 & 13 & 19 \\
\hline Costillas & - & 1. & - & 2 & - & - & - & - & - & - & 3 \\
\hline Escápula & - & 2 & - & 2 & - & - & - & - & - & 7 & 11 \\
\hline Húmero & - & 1 & 5 & 5 & - & 2 & - & - & 1 & 10 & 24 \\
\hline Radio & 1 & 4 & - & 3 & 1 & - & - & - & 1 & 3 & 13 \\
\hline Ulna & - & - & - & - & 1 & - & - & - & - & 4 & 5 \\
\hline Metacarpo & - & 3 & - & 4 & - & 1 & 1 & - & - & - & 9 \\
\hline Pelvis & 1 & 1 & - & 2 & - & - & - & - & - & 11 & 15 \\
\hline Fémur & - & 1 & - & 3 & - & - & - & - & - & 4 & 8 \\
\hline Tibia & 2 & 3 & - & 5 & - & - & - & - & - & 2 & 12 \\
\hline Tarsales & 1 & 10 & 3 & 13 & 4 & - & 1 & - & - & - & 32 \\
\hline Metatarsos & 1 & 1 & - & 4 & - & - & - & - & - & - & 6 \\
\hline Sesamoideos & 2 & 1 & - & - & - & - & - & - & - & - & 3 \\
\hline Falanges & 3 & 13 & 1 & 2 & 2 & - & 4 & 1 & 3 & - & 29 \\
\hline Otros & 1 & 2 & - & - & - & 1 & - & - & - & - & 4 \\
\hline TOTAL & 18 & 78 & 9 & 128 & 9 & 14 & 18 & 8 & .7 & 64 & 353 \\
\hline
\end{tabular}

Tabla 3.- Desglose del NR mamaliano en el Nivel II por porciones esqueléticas.

escépticos a la hora de interpretar el significado de la asociación. En el caso que nos concierne las hipótesis planteadas podrían ser posteriormente contrastadas al estudiar el resto de la muestra faunística de este yacimiento alicantino. Ello permitirá también decidir hasta qué punto resultan ciertas las afirmaciones avanzadas. 


\begin{tabular}{llcccccccccc}
\hline N. $^{\circ}$ & Categoría & Caballo & Vaca & Oveja & O/C & Cabra & Cerdo & Ciervo & Corzo & Cabra & M. Conejo \\
\hline 1 & Asta/cuerno & 0 & 0 & 0 & 11,11 & 0 & 0 & 4,76 & 0 & 4,76 & 0 \\
2 & Neurocráneo & 0 & 2,06 & 0 & 0,63 & 0 & 0 & 0 & 0 & 0 & 14,28 \\
3 & Viscerocráneo & 0 & 3,09 & 0 & 3,82 & 0 & 10,52 & 4,47 & 10,0 & 0 & 0 \\
4 & Dientes superiores & 15,0 & 12,37 & 0 & 31,84 & 0 & 0 & 0 & 10,00 & 0 & 0 \\
5 & Mandíbula & 0 & 6,18 & 0 & 15,92 & 0 & 0 & 10,44 & 20,0 & 14,28 & 0 \\
6 & Dientes inferiores & 20,0 & 18,55 & 0 & 15,28 & 0 & 36,84 & 0 & 40,0 & 38,3 & 0 \\
7 & Vértebras & 0 & 1,03 & 0 & 1,27 & 0 & 5,26 & 19,4 & 0 & 2,98 & 14,28 \\
8 & Costillas & 0 & 1,03 & 0 & 1,27 & 0 & 0 & 0 & 0 & 0 & 0 \\
9 & Escápula & 0 & 2,06 & 0 & 1,27 & 0 & 21,05 & 10,44 & 10,0 & 0 & 0 \\
10 & Húmero & 0 & 3,09 & 55,5 & 3,18 & 0 & 10,52 & 14,92 & 0 & 0 & 14,28 \\
11 & Radio & 5,0 & 5,15 & 0 & 1,91 & 11,1 & 0 & 5,97 & 0 & 0 & 14,28 \\
12 & Ulna & 0 & 0 & 0 & 0 & 11,1 & 0 & 5,97 & 0 & 0 & 0 \\
13 & Carpales & 0 & 0 & 0 & 0,63 & 0 & 0 & 0 & 0 & 0 & 0 \\
14 & Metacarpo & 0 & 4,12 & 0 & 3,18 & 0 & 5,26 & 0 & 0 & 4,76 & 0 \\
15 & Pelvis & 10,0 & 1,03 & 0 & 1,27 & 0 & 0 & 19,4 & 0 & 0 & 0 \\
16 & Fémur & 0 & 1,03 & 0 & 1,91 & 0 & 0 & 5,97 & 0 & 0 & 0 \\
17 & Tibia & 10,0 & 3,09 & 0 & 3,82 & 0 & 5,26 & 2,98 & 0 & 0 & 0 \\
18 & Tarsales & 5,0 & 13,4 & 33,3 & 8,91 & 44,4 & 0 & 0 & 0 & 14,28 & 0 \\
19 & Metatarsos & 5,0 & 2,06 & 0 & 2,54 & 0 & 0 & 0 & 0 & 0 & 0 \\
20 & Sesamoides & 10,0 & 1,03 & 0 & 0 & 0 & 0 & 0 & 0 & 0 & 0 \\
21 & Falanges & 15,0 & 17,52 & 11,1 & 1,27 & 22,2 & 0 & 0 & 10,0 & 19,04 & 42,85 \\
22 & Otros & 5,0 & 2,06 & 0 & 0 & 0 & 5,26 & 0 & 0 & 0 \\
& TOTAL & $100,0 \%$ & $100,0 \%$ & $100,0 \%$ & $100,0 \%$ & $100,0 \%$ & $100,0 \%$ & $100,0 \%$ & $100,0 \%$ & $100,0 \%$ & $100,0 \%$ \\
\hline
\end{tabular}

Tabla 4.- Desglose porcentual de porciones esqueléticas por especies (taxones). Los números de la primera columna se corresponden con los del eje de abscisas en los gráficos 3,4 y 5.

\section{SEGUNDA PARTE: DESCRIPCIÓN GENERAL}

\section{METODOLOGÍA}

\section{1) Identificación}

La identificación se ha realizado con la ayuda de la colección comparativa del laboratorio de Zooarqueología de la Unidad de Zoología de la U.A.M. Como es habitual en este tipo de trabajos, los restos de oveja o cabra que resultan ser indiferenciables entre sí se han agrupado en una categoría convencional que denominamos $\mathrm{O} / \mathrm{C}$ (Oveja o Cabra) a lo largo de todo el informe. Asimismo, el conjunto de ovicaprinos: oveja, cabra y oveja o cabra se simboliza como OVC.

\section{2) Cálculo del número mínimo de individuos, NMI.}

Para la estimación del NMI se ha utilizado el siguente método: se emplea como indicador fundamental del NMI la pieza más abundante, considerando como piezas distintas a estos efectos las de uno u otro lado en el caso de las pares; además, de modo complementario se tienen en cuenta aquellas piezas o huesos que no siendo mayoritarios ofrezcan características discriminatorias evidentes que aumenten el NMI: tamaño, edades, sexos, condiciones patológicas, etc.

\section{3) Datos biológicos complementarios: edad.}

El cálculo de la edad se ha basado fundamentalmente en los siguientes criterios relativos:

a) Fusión epifisaria

De acuerdo con los criterios de la escuela de Munich se han utilizado las siglas que siguen:

$$
\begin{aligned}
& (+)=\text { epífisis fusionada } \\
& (-)=\text { epífisis no fusionada } \\
& (+/-)=\text { epífisis en trance de fusión } \\
& (?)=\text { epífisis dañada o perdida }
\end{aligned}
$$

\section{b) Desgaste dentario}

Se siguen los criterios de la misma escuela que en el caso anterior.

$(+)=$ piezas dentarias poco gastadas

$(++)=$ piezas dentarias medianamente gastadas

$(+++)=$ piezas dentarias muy gastadas 
Esta metodología sólo es aplicable de manera rigurosa a las piezas dentarias definitivas y dentro de ciertos márgenes, dado el carácter relativo y en cierto modo algo subjetivo de estas divisiones; asimismo se ha tenido en cuenta la emergencia dentaria. La denominación de las piezas dentarias es la habitual en mastozoología: se usa la inicial de cada pieza (incisivo, canino, premolar y molar), minúscula o mayúscula según que se trate de la dentición de leche o de la definitiva, y con un superíndice o con un subíndice (según se trate de dientes superiores o inferiores) para indicar el número de orden de la pieza en cuestión. Cuando no hay ambigüedad respecto a superior o inferior, el número de orden sigue sin más a la inicial de la pieza en cuestión.

\section{4) Biometría}

Las medidas se han tomado con calibre convencional, estimando en principio hasta décimas de milímetro, y redondeando posteriormente con error menor de $0,5 \mathrm{~mm}$. No se han medido en general ni individuos juveniles, ni piezas quemadas o trabajadas ni anatomías patológicas; las excepciones se especifican expresamente. La metodología estadística seguida en su caso es la habitual, las medidas se dan en $\mathrm{mm}$.

\section{5) Siglas}

Las siglas osteométricas usadas en este trabajo se relacionan a continuación, y son las habituales en este tipo de informes, compiladas p. ej. en Miguel y Morales, 1983. Otras siglas muy comunes, empleadas con cierta frecuencia son: $\mathrm{D}$, derecho; $\mathrm{S}$, izquierdo; AP, anteroposterior; SI, sin identificar; y las ya dichas a propósito de las piezas dentarias. Los machos se representan con el símbolo $\delta$, las hembras como o y los individuos castrados como $\hat{\phi}$.

\section{MANDÍBULA}

Serie dentaria (inferior) SDI

\section{3}

Longitud (corona) L(corona)

Anchura (corona) A(corona)

\section{AXIS}

Anchura articular craneal AAC

Anchura del Dens ADE

\section{ESCÁPULA}

Longitud mínima del cuello LMC

Longitud distal LD
Longitud articular LA

Altura máxima HM

Anchura articular AA

HÚMERO

Longitud máxima LM

Anchura proximal AP

Anchura mínima de la diáfisis AMD

Anchura distal AD

Anchura troclear AT

Anchura articular distal AAD

\section{RADIO}

Anchura proximal AP

Anchura articular proximal AAP

Anchura mínima de la diáfisis AMD

Anchura distal AD

Anchura articular distal AAD

Anchura troclear AT

ULNA

Anchura articular AA

Grosor del proceso ancóneo GPA

Grosor mínimo del olecranon GMO

Longitud del olecranon LO

\section{METACARPO}

Anchura distal AD

Anchura articular distal AAD

Anchura proximal AP

\section{PELVIS}

Longitud acetabular máxima LAM

Lontitud acetabular en el borde LAB

\section{FÉMUR}

Longitud máxima LM

Anchura proximal AP

Anchura mínima de la diáfisis AMD

Anchura distal AD

\section{TIBIA}

Anchura mínima de la diáfisis AMD

Anchura distal AD 


\section{ASTRÁGALO}

Anchura de la cabeza AC

Longitud lateral LL

Longitud medial máxima LMM

Grosor lateral máximo GL

CALCÁNEO

Longitud máxima LM

Anchura máxima AM

\section{CENTROTARSAL}

Anchura máxima AM

\section{METATARSO}

Anchura proximal AP

Anchura distal

$\mathrm{AD}$

Anchura articular distal.

F I, II, y III

Longitud máxima LM=LMP

Longitud dorsal LD

Anchura proximal AP

Anchura articular AA

Anchura distal AD

Anchura articular distal AAD

Anchura mínima de diáfisis AMD

\section{RESULTADOS}

La fauna de este yacimiento está representada en esta muestra escogida por 429 restos de vertebrados. A continuación se ofrecen unas tablas con las proporciones de las distintas especies en el yacimiento, tanto en cuanto a número de restos como en cuanto a número mínimo de individuos, para cada nivel y para la totalidad del yacimiento. Aparecen unas pequeñas diferencias con respecto a las tablas ofrecidas en la primera parte del informe, de tipo metodológico. La razón de esta diferencia es la siguiente: según hemos señalado reiteradamente, tanto en la primera como en la segunda parte, el profesor González Prats había hecho una selección previa de los restos animales incluyendo sólo aquellos que por su mayor tamaño o menor fragmentación estimó más adecuados para nuestra labor. Por este motivo, unos pocos fragmentos, en especial algunos de reciente fractura, que se salían de este patrón, fueron de momento dejados de lado, para de esta manera establecer un análisis metodológico sobre piezas seleccionadas con criterios uniformes, de modo y manera que el sesgo «cultural» inducido fuera constante y el análisis metodológico coherente. Cabe asimismo señalar que este número ínfimo de restos no añaden ninguna información sobre distribución de sexos, edades, NMI, ni tampoco los valores de proporciones de las distintas especies en valores que supusieran alguna modificación apreciable. Por mor de exactitud incluimos estos pocos restos en esta segunda parte del informe, aunque, insistimos, el panorama general permanece inalterado.

\begin{tabular}{lrrcr}
\hline Especie & NR & \multicolumn{1}{c}{$\%$} & NMI & \multicolumn{1}{c}{$\%$} \\
\hline Equus caballus & 2 & 3,17 & 1 & 7,14 \\
Bos taurus & 19 & 30,16 & 3 & 21,43 \\
O/C & 29 & 46,03 & 6 & 42,86 \\
Sus domesticus & 5 & 7,94 & 1 & 7,14 \\
Oryctolagus cuniculus & 3 & 4,76 & 1 & 7,14 \\
Cervus elaphus & 3 & 4,76 & 1 & 7,14 \\
Capreolus capreolus & 2 & 3,17 & 1 & 7,14 \\
TOTAL & 63 & 100,00 & 14 & 100,00 \\
\hline
\end{tabular}

Relación de restos de Vertebrados. Corte «E». Nivel I.

\begin{tabular}{lrrrr}
\hline Especie & NR & $\%$ & NMI & $\%$ \\
\hline Equus caballus & 19 & 5,19 & 3 & 7,14 \\
Bos taurus & 85 & 23,22 & 4 & 9,52 \\
Ovis aries & 9 & 2,46 & 3 & 7,14 \\
O/C & 132 & 36,07 & 12 & 28,57 \\
Capra hircus & 9 & 2,46 & 3 & 7,14 \\
OVC & 150 & 40,98 & 18 & 42,86 \\
Sus domesticus & 14 & 3,83 & 2 & 4,76 \\
Oryctolagus cuniculus & 64 & 17,49 & 6 & 14,29 \\
Cervus elaphus & 18 & 4,92 & 5 & 11,90 \\
Capreolus capreolus & 8 & 2,19 & 2 & 4,76 \\
Capra pyrenaica & 7 & 1,91 & 1 & 2,38 \\
Ave & 1 & 0,27 & 1 & 2,38 \\
TOTAL & 366 & 100,00 & 42 & 100,00 \\
\hline
\end{tabular}

Relación de restos de Vertebrados. Corte «E». Nivel II.

\begin{tabular}{lrrrr}
\hline Especie & NR & \multicolumn{1}{c}{$\%$} & NMI & \multicolumn{1}{c}{$\%$} \\
\hline Equus caballus & 21 & 4,90 & 4 & 7,14 \\
Bos taurus & 104 & 24,24 & 7 & 12,50 \\
Ovis aries & 9 & 2,10 & 3 & 5,36 \\
O/C & 161 & 37,53 & 18 & 32,14 \\
Capra hircus & 9 & 2,10 & 3 & 5,36
\end{tabular}


OVC

Sus domesticus

179

19

$$
41,72
$$

67

Cervus elaphus

67

$$
4,43
$$

$24 \quad 42,86$

$3 \quad 5,36$

Capreolus capreolus

$$
15,62
$$

12,50

$$
4,90
$$

$10 \quad 2,33$

1,63

0,23

$429 \quad 100,00$

Ave

7
1

TOTAL

$\begin{array}{lll}429 & 100,00 \quad 56 \quad 100,00\end{array}$

Relación general de restos de Vertebrados. Corte «E».

\section{PEÑA NEGRA. CORTE E. NIVEL I}

\section{Equus caballus L. Caballo.}

Representado tan sólo por un $\mathrm{M}^{\mathrm{y}} / \mathrm{M}^{2}$, con desgaste $(+++)$, lo que indica un individuo adulto, y por un fragmento de pelvis: porción de acetábulo isquiopúbico de una hemipelvis $\mathrm{D}$. NMI $=1$.

\section{Bos taurus L. Vaca.}

A) Relación de restos

$\begin{array}{lr}\text { Neurocráneo } & 2 \\ \text { Viscerocráneo } & 1 \\ \text { Dientes sup. } & 2 \\ \text { Dientes inf. } & 2 \\ \text { Húmero } & 2 \\ \text { Radio } & 1 \\ \text { Metacarpo } & 1 \\ \text { Astrágalo } & 3 \\ \text { Metatarso } & 1 \\ \text { F I } & 3 \\ \text { F II } & 1 \\ \text { Total } & 19\end{array}$

\section{B) Descriptiva}

La pieza que fija en su valor más alto el NMI es el astrágalo. Dos de ellos son $\mathrm{S}$, y el $\mathrm{D}$, por su distinto tamaño, no puede emparejarse con ninguno de los dos; $\mathrm{NMI}=3$, pues. De ellos dos parecen ser $\hat{\delta}, \mathrm{y}$ el otro es de una $q$. Este reparto de sexos viene indicado por las falanges I. En cuanto a lo que se refiere a edades, tanto un $\mathrm{M}^{1 /} \mathrm{M}^{2}$ con desgaste $(+++)$ como un $\mathrm{P}^{3} \mathrm{D}$ con desgaste $(++)$ indican un adulto, $\mathrm{y}$ un $\mathrm{P}^{3} \mathrm{D}$ con desgaste $(+++)$ proviene de un adulto viejo o senil; la edad del tercer individuo no puede conjeturarse.
C) Medidas

Húmero

$\mathrm{AD} \quad 88$

AT 81

D/S D

Radio

AP

$\mathrm{D} / \mathrm{S}$

D

Astrágalo

LL

(66) $63 \quad-$

LM

(62) $58 \quad 52$

GL

$\mathrm{AC}$

$\mathrm{D} / \mathrm{S}$

- 35 -

(44) $43,5-$

F I

AP

D S S

AMD 21

$\mathrm{AD} 23$

FII

$\delta / \%$

q

AP

AMD

\section{Oveja o Cabra O/C.}

\section{A) Relación de restos}

Viscerocráneo

Dientes sup.

Dientes inf.

Carpo

Metacarpo

Tibia

Calcáneo

Total

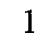

1

1

1

29

B) Descriptiva

El NMI viene fijado por las piezas dentarias. De los dientes superiores hay $5 \mathrm{M}^{3}, 4 \mathrm{~S}$, dos de ellos con desgaste $(++)$ y dos con desgaste $(++/+++)$, a la vez que el $\mathrm{D}$ tiene desgaste distinto $(+)$ de todos ellos, y pertenece a un $5^{\circ}$ individuo. Además en la serie inferior hay entre otros elementos un $\mathrm{M}^{3} \mathrm{D}$, con desgaste $(+++)$, de un individuo senil. Así pues, NMI=6, de edades: un aduto senil, ya citado, dos adultos seniles ? (2 $\mathrm{M}^{3} \mathrm{~S}(++/+++)$, dos adultos de no mucha edad (2 $\left.\mathrm{M}^{3} \mathrm{~S}++\right)$, y un subadulto $\left(\mathrm{M}^{3} \mathrm{D}+\right.$, confirmado por el metacarpo, con epífisis distal (-), indicio de edad menor de 30 meses. 
C) Medidas

Tibia

$\mathrm{AD}$

Epíf.

23

(-)

Sus domesticus L. Cerdo.

Estos restos, asignados a SJU-S-11 d, son 4 escápulas (1 porción distal S y 3 fragmentos de lámina) y una tibia casi entera, es más exactamente una porción proximal con epífisis proximal (+) y distal (-), lo que indica edad mayor de 42 meses, adulto pues. De hecho la epífisis distal se fusiona antes que la proximal, y debemos suponer que estaría, antes de la fragmentación fusionada. Hay que señalar que pese a pertenecer según estos datos a un adulto, se corresponde con una talla muy pequeña.

\section{Oryctolagus cuniculus L. Conejo.}

Representado por 1 porción proximal de radio D y 2 pelvis, 1 porción acetabular isquiática $\mathrm{D}$ y 1 acetábulo ilíaco $\mathrm{S}$, todo ello muy verosímilmente de un solo individuo. Se han podido tomar las siguientes medidas:

Radio

$\begin{array}{lr}\text { AP } & 6 \\ \text { AMD } & 3,5 \\ \text { D/S } & D\end{array}$

Pelvis
LAM
LAB
$\mathrm{D} / \mathrm{S}$
$\mathrm{S}$

Capreolus capreolus (L) Corzo.

Representado por $1 \mathrm{M} / \mathrm{M}^{2} \mathrm{D}$, con desgaste extremo $(+++)$, que indica un individuo senil, y por una porción articular distal de una escápula.

\section{Cervus elaphus L. Ciervo.}

Representado por un fragmento de la apófisis neural de una vértebra lumbar, y por 2 fragmentos distales de calcáneo, uno $\mathrm{D}$ y otro $\mathrm{S}$. $\mathrm{NMI}=1$.

\section{CORTE E. NIVEL II}

\section{Equus caballus L. Caballo.}

A) Relación de restos

$\begin{array}{lr} & \text { NR } \\ \text { Dientes sup. } & 3 \\ \text { Dientes inf. } & 4 \\ \text { Radio } & 1 \\ \text { Pelvis } & 1 \\ \text { Tibia } & 2 \\ \text { Tarsal } & 1 \\ \text { Metatarso } & 1 \\ \text { Sesamoideo } & 2 \\ \text { Falange I } & 2 \\ \text { Falange III } & 1 \\ \text { Metapodio } & 1 \\ \text { Total } & 19\end{array}$

B) Descriptiva

Los 19 restos de caballo recuperados corresponden a un $\mathrm{NMI}=3$. Uno de los cuales es un subadulto, aproximadamente de 42 meses, según se deduce de una porción proximal $\mathrm{D}$ de tibia en trance de fusión $(+/-)$. Los dos individuos restantes son adultos; uno mayor de 42 meses (Radio: una porción distal D, epífisis (+). Tibia: una porción proximal D, epífisis (+) y el segundo supera la edad de 54 meses, con posibilidad de que sea un individuo senil dada la presencia de un $\mathrm{M}^{3} \mathrm{~S}$ con desgaste $(+++)$.

Un acetábulo $S$ de pelvis recuperado parece indicar la posibilidad de que uno de los citados individuos sea una hembra.

No se ha observado ninguna modificación postmortem en los elementos óseos del caballo.

C) Métrica

Radio

$\mathrm{AD}$

AAD

$\mathrm{D} / \mathrm{S}$

Metatarso

AAD

$\mathrm{D} / \mathrm{S}$

\section{$\mathrm{S}$}

Falange I

LM

AP

46,5

AMD

32,0

$\mathrm{AD}$ 
$\mathrm{AAD}$

$\mathrm{a} / \mathrm{p}$

$\mathrm{D} / \mathrm{S}$

Bos taurus L. Vaca.

A) Relación de restos:

Viscerocráneo

NR

Dientes sup.

Mandíbulas

Dientes inf.

Axis

Costilla

Escápula

Húmero

Radio

Carpal

Metacarpo

Pelvis

Fémur

Tibia

Astrágalo

Calcáneo

Centro tarsal

Metatarso

Falange I

Falange II

Falange III

Metapodio

Maleolar

Total

B) Descriptiva

Las piezas dentarias recuperadas nos indican la presencia de un total de cuatro individuos. Según la emergencia y el desgaste de dichas piezas se puede inferir la presencia de:

- Un individuo infantil-juvenil, mayor de cinco meses $\left(1 \mathrm{M}^{1} / \mathrm{M}^{2}[+/-]\right)$

- Un individuo juvenil-subadulto de aproximadamente 24 meses $\left(1 \mathrm{M}^{3} \mathrm{D}[+/-]\right)$.

- Y dos individuos adultos, de edad superior a 24 meses (dos $\mathrm{M}^{3}$, uno $\mathrm{D}$ el otro $\mathrm{S}$ ). El diferente desgaste de estos $\mathrm{M}^{3}([++]$ y $[+++]$ respectivamente) nos refleja la posible existencia de un individuo senil. Los huesos post-craneales nos han permitido precisar algo más la edad de los dos individuos adultos consigna-

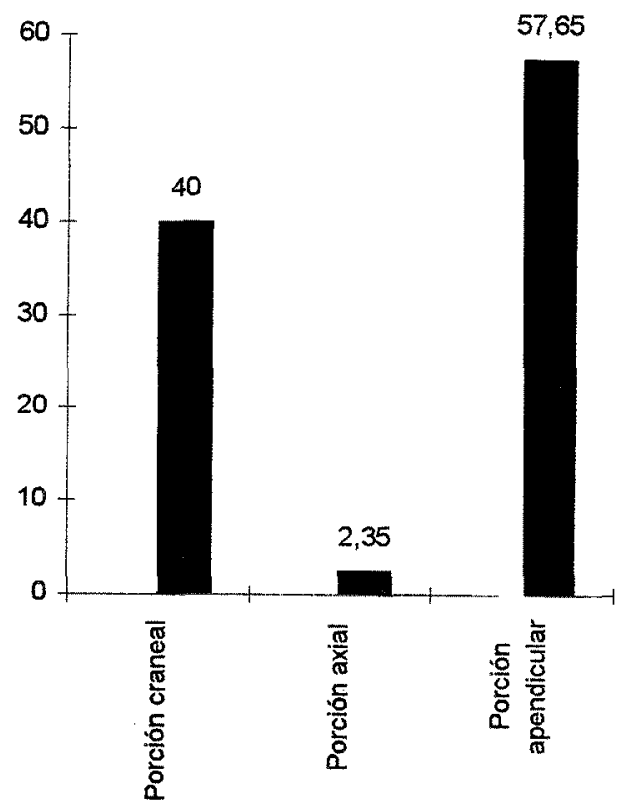

dos; uno de ellos podría incluso ser mayor de 30 meses (1 metacarpo epífisis [+]) y el otro de edad superior a los 48 meses (Tibia: una porción proximal D, epífisis [+], Fémur: una porción distal $[+])$.En cuanto a sexo se refiere parecen encontrarse representados machos, hembras e incluso individuos castrados.

C) Métrica

Axis

$$
\text { AAC }
$$

ADE

Escápulas

LMC

$49,5 \quad 46,0$

LD

$(64,0) \quad(58,5)$

LA

$(54,0) \quad(50,5)$

AA

$\mathrm{D} / \mathrm{S}$

$45,0 \quad 42,5$

Tuber

S S

(t) (+)

Húmero

AT

$(68,0)$

D/S

D

Radio

$\mathrm{AD}$

55,5

D/S

$\mathrm{S}$

Metacarpo

AP

50,0

$\mathrm{D} / \mathrm{S}$ 
Tibia
$\mathrm{AD}$
$(60,0)$
$\mathrm{D} / \mathrm{S}$ $\mathrm{S}$

Astrágalo

$\begin{array}{lccrc}\text { LL } & 53,0 & 60,5 & - & (65,0) \\ \text { LM } & 48,5 & - & 57,5 & 58,0 \\ \text { GL } & 29,0 & 33,5 & - & 36,2 \\ \text { AC } & 35,5 & 37,0 & - & 43,0 \\ \text { D/S } & \mathrm{S} & \mathrm{S} & \mathrm{D} & \mathrm{D}\end{array}$

Centro tarsal
AM
49,5
$\mathrm{D} / \mathrm{S}$
$\mathrm{D}$

la muestra analizada en este nivel. Ello se debe a que contamos con 4 porciones distales de las cuales 3 son derechas (y $1 \mathrm{~S}$ ); puede decirse que todas serían de individuos con más de 9 meses, y a juzgar por un fragmento de porción proximal que puede relacionarse con una de ellas, al menos 1 sería mayor de 42 meses. Si relacionamos estos datos con las edades mínimas proporcionadas por los restos de calcáneos, estaremos ante dos individuos adultos ( 1 mayor de 30 meses y 1 mayor de 42 meses); mientras que de 1 tercer individuo no se podría precisar más la cohorte de edad; salvo decir que tendría más de 9 meses.

C) Métrica

Húmero

$\begin{array}{lrrr}\text { AD } & (33,0) & (30,5) & (27,0) \\ \text { AAD } & (32,0) & (29,0) & (25,5) \\ \text { D/S } & \text { D } & \text { D } & \text { D }\end{array}$

Astrágalo

LL 26,5

$\mathrm{LM}$ 24,5

GL $\quad 14,5$

$\mathrm{AC} \quad 18,5$

$\mathrm{D} / \mathrm{S}$

$$
\text { S }
$$

Calcáneo

LM

AM

$\mathrm{D} / \mathrm{S}$

$49,5 \quad 50,5$

- $\quad 16,0$

Tuber

D

D

Falange II

LM

21,0

AP

11,5

AMD

9,0

$\mathrm{AD}$

9,0

A) Relación de restos

$\begin{array}{ll}\text { Húmero } & 5 \\ \text { Astrágalo } & 1 \\ \text { Calcáneo } & 2 \\ \text { Falange II } & 1 \\ \text { Total } & 9\end{array}$

\section{B) Descriptiva}

Atendiendo al estudio de los calcáneos, obtenemos un $\mathrm{NMI}=2$, ya que las dos piezas son derechas. Ambas presentan el tubérculo ( + ) por lo que representarían a individuos con más de 30 meses.

El estudio pormenorizado de los restos de húmero nos permite elevar a 3 el número de individuos de

\section{Ovicápridos.}

A) Relación de restos

$\begin{array}{lr}\text { Neurocráneo } & 2 \\ \text { Viscerocráneo } & 4 \\ \text { Diente superior } & 37 \\ \text { Mandíbula } & 25 \\ \text { Diente inferior } & 14 \\ \text { Axis } & 1 \\ \text { Vert. costal } & 1 \\ \text { Costilla } & 2 \\ \text { Escápula } & 2 \\ \text { Húmero } & 5\end{array}$




$\begin{array}{lr}\text { Radio } & 3 \\ \text { Metacarpo } & 4 \\ \text { Pelvis } & 2 \\ \text { Fémur } & 3 \\ \text { Tibia } & 5 \\ \text { Astrágalo } & 9 \\ \text { Calcáneo } & 3 \\ \text { Centrotarsal } & 1 \\ \text { Metatarso } & 7 \\ \text { Falange I } & 2 \\ \text { Total } & 132\end{array}$

\section{B) Descriptiva}

El estudio de los restos de escápula hace pensar en 2 individuos, ya que ambos fragmentos son derechos. Este primer NMI aumenta si nos fijamos en los restos de húmero; se trata de 5 restos de los cuales 3 son derechos y 2 son izquierdos (todos ellos porciones distales), por lo que nuestro NMI ascendería aquí a 3 . El mismo resultado obtenemos de los restos de radio, si bien en este apartado las diferencias se han establecido esencialmente atendiendo a diferencias de talla, como también ocurre en el caso de los restos de metacarpos. Los dos restos de pelvis (fragmentos acetabulares isquiáticos de igual asignación parasagital). Según los restos de fémur volvemos a tener 3 individuos por diferencias de talla y lo mismo sucede en las tibias, (todas fragmentos de diáfisis), que son $2 \mathrm{D}$ y $3 \mathrm{~S}$ ( 1 de estas últimas presenta también parte de la porción distal por lo que puede apreciarse que su epífisis está en trance de fusión $(+/-)$, lo que nos indica un individuo de unos 18 meses). Los calcáneos nos proporcionan la misma cifra ya que pese a ser $2 \mathrm{D}$ y $1 \mathrm{~S}$, presentan diferencias de talla, pese a ser todos ellos menores de 30 meses (tienen el tuber [-]).

El NMI que obtenemos del estudio de los astrágalos es de 7 , de los 9 restos de astrágalo, 7 son derechos.

Pero el valor más alto para el NMI se obtiene del estudio de los restos de dientes.

Como puede verse en la relación de restos, el número de dientes o fragmentos de estos es considerable en relación a la muestra presentada, especificar aquí los datos referentes a cada uno de ellos sería excesivamente extenso, por lo que nos limitaremos a comentar brevemente algunos aspectos destacables. El estudio de los restos de mandíbula y dientes inferiores nos lleva a un NMI= 12 individuos, que en su mayoría serían juveniles/subadultos; encontrándonos sólo un individuo de

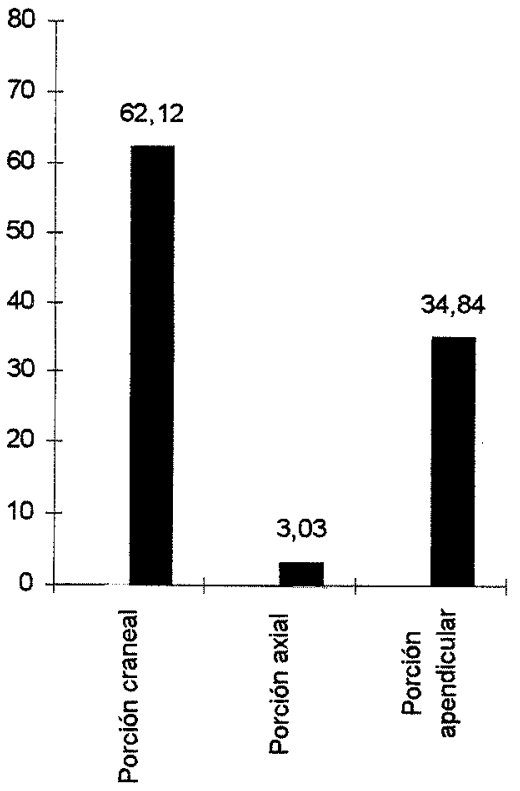

corta edad, representado por fragmentos de dientes de leche (dtes. superiores) y $1 \mathrm{p} 4$ inferior que se encontraba emergiendo, por lo que la edad de este individuo se aproximaría a las 6 semanas. El resto de las cohortes de edad representadas están definidas por los siguientes restos: 4 individuos con $\mathrm{p} 4$ con $(++)$; 1 individuo representado por $1 \mathrm{M}_{2}(+/-)$, con unos 11 meses; 1 individuo representado por $1 \mathrm{M}_{3}(+)$ y por lo tanto mayor de 25 meses; 4 individuos con $\mathrm{M}_{3}(++)$, es decir con mayor desgaste y por lo tanto mayores que el individuo inmediatamente anterior; y finalmente 1 individuo representado por $1 \mathrm{M}_{3}(+++)$, que ya podría considerarse senil.

C) Métrica

$\mathrm{M}_{3}$

$\begin{array}{lrrrrrr}\text { L (corona) } & 23,5 & 20,0 & 19,5 & 19,5 & - & - \\ \text { A (corona) } & 7,0 & 7,5 & (7,0) & 7,5 & 8,0 & 8,5 \\ \text { D/S } & \text { D } & \text { D } & \text { S } & \text { S } & \text { S } & \text { S } \\ \text { Desgaste } & (++) & (++) & (++) & (+++) & (++) & (++)\end{array}$

Húmero

$\mathrm{AD}$

28,5

AT

28,0

28,5

$\mathrm{D} / \mathrm{S}$

$\mathrm{D} S$

Radio

AP 28,0

AAP 26,5

$\mathrm{D} / \mathrm{S} \quad \mathrm{S}$ 
Tibia

$\begin{array}{ccccc}\mathrm{AD} & 23,0 & 25,5 & 24,5 & 22,5 \\ \mathrm{D} / \mathrm{S} & \mathrm{D} & \mathrm{D} & \mathrm{S} & \mathrm{S}\end{array}$

Astrágalo

$\begin{array}{lrrr}\text { LL } & 26,0 & 26,0 & 26,0 \\ \text { LM } & 24,0 & 24,0 & 24,0 \\ \text { GL } & 14,0 & (13,5) & 14,0 \\ \text { AC } & 16,5 & 17,0 & (17,0) \\ \text { DS } & \text { D } & \text { D } & \text { D }\end{array}$

Centro tarsal

AM

23,0

$\mathrm{D} / \mathrm{S}$

D

Metatarso

$\begin{array}{lrrr}\mathrm{AP} & (19,0) & (20,0) & - \\ \mathrm{AD} & - & - & 20,0 \\ \mathrm{D} / \mathrm{S} & \mathrm{S} & \mathrm{D} & \mathrm{S}\end{array}$

\section{Capra hircus L., Cabra.}

A) Relación de restos

Cuerno

Radio-cúbito 1

Ulna

Astrágalo 3

Calcáneo 1

Falange II 2

Total

B) Descriptiva

La porción articular de radio - cúbito, presenta una patente exostosis, ocasionada posiblemente tras una fractura.

Otro fragmento de ulna (una porción proximal derecha) presenta el olécranon $(+)$, por lo que hace referencia a un individuo mayor de 42 meses.

El NMI de esta especie en este nivel, lo proporcionan los restos de astrágalo (3 derechos).

C) Métrica

Ulna

$\begin{array}{lr}\text { AA } & 22,0 \\ \text { GPA } & 24,0 \\ \text { GMO } & 19,5 \\ \text { LO } & 38,0 \\ \text { D/S } & \text { D }\end{array}$

Astrágalo

$\begin{array}{lrrr}\text { LL } & 25,0 & 28,5 & 26,5 \\ \text { LM } & (24,0) & 26,0 & (24,5)\end{array}$
GL
$(14,5) \quad 15,0$
13,5
$\mathrm{AC}$
$16,5 \quad 19,0 \quad 17,0$
$D / S$
D D
D

Falange II

LM

AP

AMD

$\mathrm{AD}$

$(10,0) \quad 9,5$

Otros Quemada

\section{Sus domesticus L., Cerdo.}

A) Relación de restos

Viscerocráneo

Diente inferior

Diente s. espfcar.

Atlas

Húmero

Metacarpo III

Metapodio

Total

2
4
1
1
2
1
1
12

B) Descriptiva

Los dos fragmentos de viscerocráneo pertenecen a 2 maxilares derechos: 1 con $\mathrm{P}^{4}$ y $\mathrm{M}^{1}$, así como alveolos de $\mathrm{M}^{2}$ y $\mathrm{M}^{3}$; y 1 con $\mathrm{P}^{3}$ y $\mathrm{P}^{4}$.

Entre los dientes inferiores hay que destacar 1 fragmento de $\mathrm{M}^{3}$ aún germen por lo que pertenecería a un individuo cercano a los 20 meses.

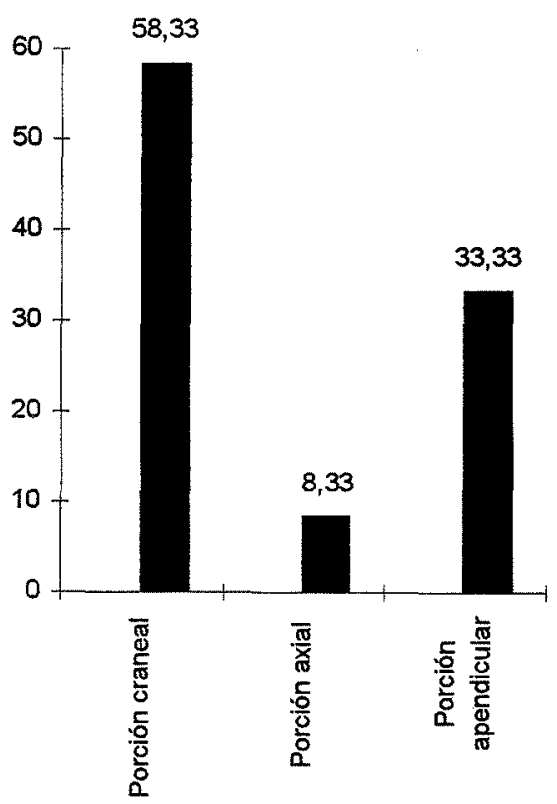


Como ocurre en el caso de los restos de viscerocráneo, el estudio de los húmeros también proporciona un $\mathrm{NMI}=2$; ya que ambos húmeros son derechos. Ambos individuos serían adultos.

C) Métrica

AD

AD

$\mathrm{AAD}$

31,0

$\mathrm{D} / \mathrm{S}$

\section{Oryctolagus cuniculus L. Conejo.}

A) Relación de restos

$\begin{array}{lr}\text { Viscerocráneo } & 3 \\ \text { Mandíbula } & 7 \\ \text { Atlas } & 1 \\ \text { Vértebra cervical } & 1 \\ \text { Vértebra costal } & 1 \\ \text { Vértebra lumbar } & 9 \\ \text { Sacro } & 1 \\ \text { Escápula } & 7 \\ \text { Húmero } & 10 \\ \text { Radio } & 3 \\ \text { Ulna } & 4 \\ \text { Pelvis } & 11 \\ \text { Fémur } & 4 \\ \text { Tibia } & 2 \\ \text { Total } & 64\end{array}$

B) Descriptiva

Como ya hemos señalado en las consideraciones metodológicas destaca la ausencia de todas las piezas por debajo de un tamaño crítico, resultado de una selección previa de la muestra. Para el histograma detallado de las distintas proporciones de las piezas esqueléticas puede consultarse el citado apartado. El NMI, 6, puede establecerse a partir de varias porciones: las mandíbulas son todas S, pero una de ellas es una porción ascendente que puede tal vez corresponderse con una rama alveolar; de los húmeros hay $6 \mathrm{D}, 2$ completos y 4 porcio- nes distales de diáfisis, todas ellas de individuos distintos; entre las pelvis hay asimismo $6 \mathrm{D}$, que aunque no todas completas, sí son manifiestamente de individuos distintos. En cuanto a edades, de las 9 vértebras lumbares hay 2 con ambas epífisis ( + ), 2 con ambas (-), y 5 con la anterior (-) y la posterior $(+)$, esto es un adulto viejo, un adulto no excesivamente añoso y un individuo infantil/subadulto; más edades no pueden fijarse. La presencia del conejo en esta muestra del Nivel II es importante, pues supone el $18,13 \%$ del total del NR, por detrás de $\mathrm{O} / \mathrm{C}(36,26 \%)$ y de la vaca $(22,10 \%)$ tan solo.

C) Medidas

Mandíbula

$\begin{array}{lccc}\text { SDI (en alv.) } & 13,5 & 14 & 14 \\ \mathrm{D} / \mathrm{S} & \mathrm{S} & \mathrm{S} & \mathrm{S}\end{array}$

Escápula

LM

$$
58,5
$$

LD

LMC

$$
\begin{array}{lll}
10,5 & 10,0 & 10,5
\end{array}
$$

AA

D/S

Radio

AP

AMD

$\mathrm{D} / \mathrm{S}$

Ulna

AA

GPA

GMO

LO

$\mathrm{D} / \mathrm{S}$

Fémur

LMF

AP

4,5

$4,5 \quad 4,5$

7,5

7,5

6,5

D D

D

$\begin{array}{ccc}6,0 & 6,0 & 5,5 \\ 4,5 & 4,0 & 3,0 \\ \mathrm{~S} & \mathrm{~S} & \mathrm{~S}\end{array}$

$\begin{array}{cc}5,5 & 5,5 \\ 7,5 & - \\ 7,0 & (7,5) \\ 7,0 & (7,5) \\ \text { D } & \text { D } \\ & \\ 78,5 & - \\ 18,0 & - \\ 6,0 & - \\ 13,5 & 12,5 \\ \text { S } & \text { D }\end{array}$

Tibia

AMD

$\mathrm{AD}$

$\mathrm{D} / \mathrm{S}$

AMD

$\begin{array}{cc}5,0 & 5,0 \\ 10,0 & 10,5 \\ \text { S } & \text { D }\end{array}$

$\mathrm{AD}$

$\mathrm{D} / \mathrm{S}$

\section{5,5}

7,0

$(7,0)$

$(7,0)$

$\mathrm{S}$

5,5

7,5

8,0

8,0

$\mathrm{S}$

Húmero

\section{LM}

AP

AMD

AD

D/S

Ep. pr.

$$
4,0
$$

9,0

$\mathrm{D} / \mathrm{H}$

(+)

\section{$-$}

8,5

D

(-)

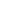


Pelvis

$\begin{array}{lccccccccccc}\text { LAM } & (8,5) & (7,5) & (8,0) & (8,0) & (7,5) & (8,5) & (7,5) & (9,0) & (8,0) & (7,5) & (8,5) \\ \text { LAB } & (7,0) & (7,5) & - & (7,0) & (6,0) & (7,0) & (7.0) & (7.5) & (7,0) & (7,0) & (7,5) \\ \text { D/S } & \text { D } & \text { D } & \text { D } & \text { D } & \text { D } & \text { D } & \text { S } & \text { S } & \text { S } & \text { S } & \text { S }\end{array}$

Cervus elaphus L. Ciervo.

A) Relación de restos

$\begin{array}{lr}\text { Asta } & 1 \\ \text { Viscerocráneo } & 1 \\ \text { Mandíbula } & 3 \\ \text { Dientes inferiores } & 6 \\ \text { Vértebra lumbar } & 1 \\ \text { Metacarpo } & 1 \\ \text { Astrágalo } & 1 \\ \text { F I } & 1 \\ \text { F II } & 1 \\ \text { F III } & 2 \\ \text { Total } & 18\end{array}$

B) Descriptiva

Como en la especie anterior, recomendamos la lectura del susodicho apartado previo de carácter metodológico que aclara la naturaleza de los restos objeto de este informe. El NMI puede establecerse como sigue: Tenemos dos ramas mandibulares $\mathrm{S}$, con P3 y P4 ambas, 2 individuos ya; hay además 2 M/1/M D y una rama mandibular $D$ con $M_{1}(+++)$ y $\mathrm{M}_{2}(++)$ incompatibles entre sí, y si bien la rama $D$ puede ser compatible con alguna de las $\mathrm{S}$, el $\neq$ tamaño y desgaste de los M1/M2 sueltos $(++)$ con los de la rama $D$ por una parte y con el M2 conservado por una de las ramas $S$, hace que ahí surja obligadamente un $3^{\text {u }}$ individuo. Por otro lado, dos $p_{4}$, de leche, uno $D$ y otro $S$ pertenecen a dos individuos, distintos entre sí, pues el $S$ tiene un desgaste $(+++)$ y el $\mathrm{D}(++)$, y distintos de los anteriores, por pertenecer a individuos de otra cohorte de edad. Resumiendo: $\mathrm{NMI}=5,3$ adultos, señalados por las distintas combinaciones de ramas mandibulares y M1/M2 inferiores D, y 2 subadultos que se deducen de los premolares, de leche, pero al ser $\mathrm{p}_{4}$, diente de emergencia tardía y estar muy o muy muy gastados excluyen a infantiles e incluso, con toda verosimilitud a juveniles.

C) Medidas

Metacarpo

$\mathrm{AD}$

37,5
$\mathrm{AAD}$

$\mathrm{D} / \mathrm{S}$

37,5

Astrágalo

LM

43,0

GL

$\mathrm{AC}$

$\mathrm{D} / \mathrm{S}$

F I

LM

AP

52,2

AMD

$\mathrm{AD}$

$(16,0)$

18,5

F II

LM

38,0

AP

19,5

AMD $\quad 14,0$

$\mathrm{AD}$

16,5

F III

LM

45

LD

AA

LMC

\section{Capreolus capreolus L. Corzo.}

Los pocos restos de esta especie son 2 p3 p4, con desgaste $(++)$ ambos, y dos ramas mandibulares, una $\mathrm{D}$ y otra $S$, pero el distinto tamaño de ramas mandibulares y dientes homólogos, indica la existencia de un $\mathrm{NMI}=$ 2 , infantiles a subadultos jóvenes, y como más probables juveniles. Hay además un maxilar D y $1 \mathrm{~F}$ III.

\section{Capra pyrenaica. Schinz. Cabra montés.}

A) Relación de restos

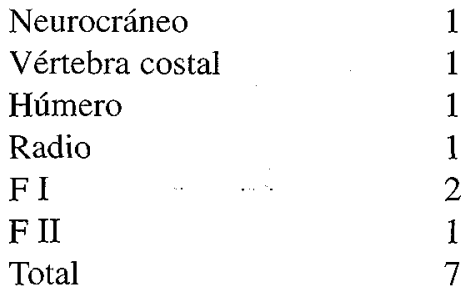


B) Descriptiva

Las dos falanges II pertenecen a dos individuos distintos, pues una de ellas tiene la epífisis sin fusionar y la otra fusionada (subadulto/adulto). Como además la vértebra costal tiene el arco neural sin fusionar a su correspondiente centro se trata de un individuo (el primero) muy joven.

C) Medidas

\section{Radio}

AP 34

AMD

$\mathrm{D} / \mathrm{S}$

F I

GLP 40,5

AP

14,5

AMD

12,0

AD

14,5

F II

LM

26,5

AP

14,5

AMD

10,5

$\mathrm{AD}$

11,0

Ave

Hay un radio $\mathrm{D}$ de un paseriforme, que por su tamaño podría ser un córvido de tamaño medio.
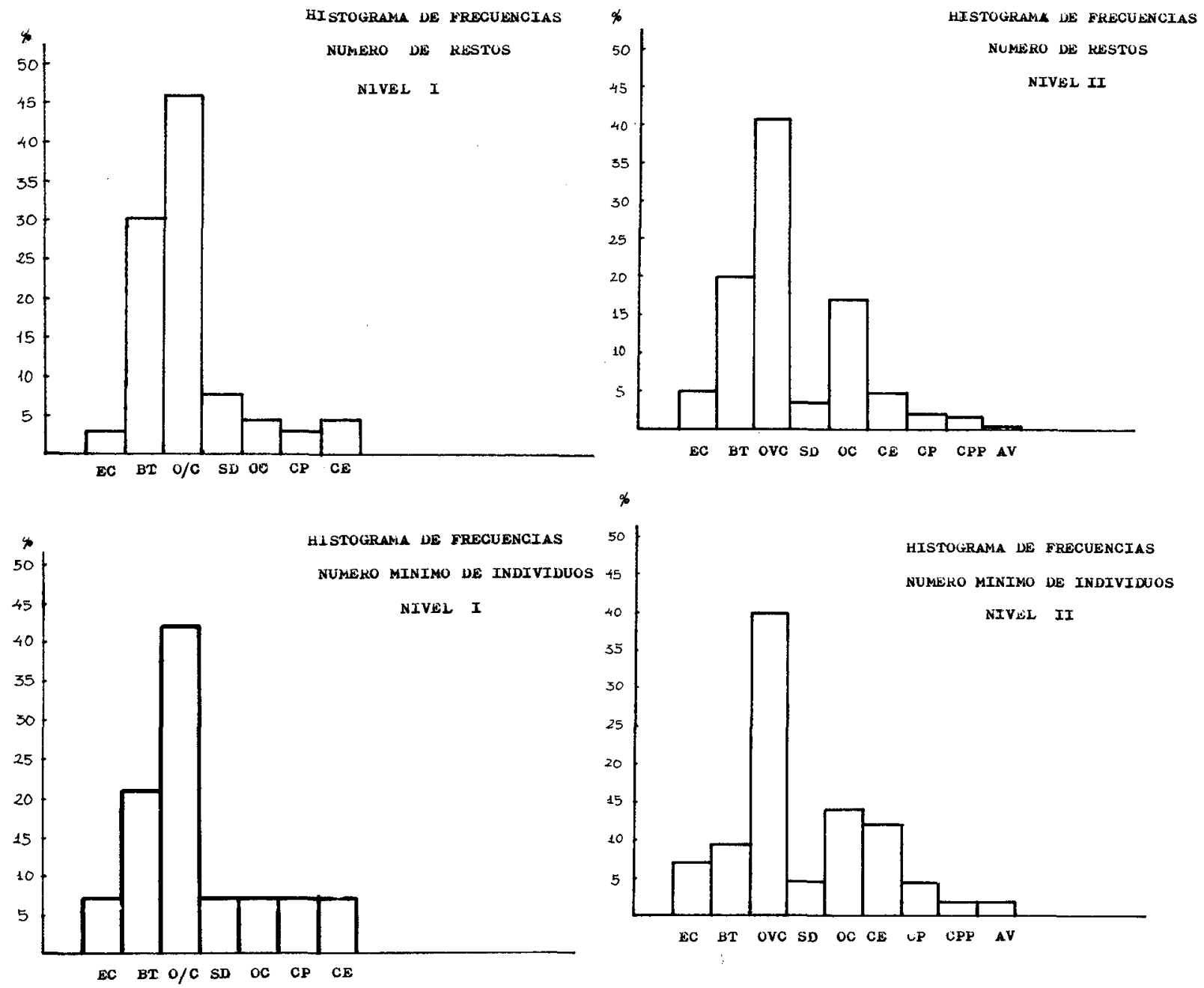


\section{RELACIÓN DE SIGLAS UTILIZADAS EN LOS HISTOGRAMAS}

\author{
$\mathrm{EC}=$ Equus caballus \\ $\mathrm{BT}=$ Bos taurus \\ OVC $=$ Ovicaprinos (total) \\ $\mathrm{SD}=$ Sus domesticus \\ $\mathrm{OC}=$ Oryctolagus cuniculus \\ $\mathrm{CE}=$ Cervus elaphus \\ $\mathrm{CP}=$ Capreolus capreolus \\ $\mathrm{CPP}=$ Capra pyrenaica \\ $\mathrm{AV}=$ Ave
}

\section{DISCUSIÓN}

El nivel I, perteneciente al Hierro Antiguo, presenta un menor número de restos que el nivel II, perteneciente al Bronce Final (GONZÁLEZ PRATS, A. com. per.); no obstante estableceremos una relación entre los resultados obtenidos a partir de ambas muestras. Al ser menor el total del NR en el primer caso, el cálculo del NMI nos lleva a una aparente homogeneidad en las especies menos representadas en la muestra, por contraposición a lo que ocurre en el Nivel II. A pesar de todo ello podemos ver que en ambos niveles, los ovicaprinos son las especies más abundantes situándose muy por encima de la especie que le sigue, claramente Bos taurus en el Nivel I, mientras que en el Nivel II este segundo lugar parece compartido por el vacuno y lagomorfos; como puede verse en los histogramas de este Nivel II, los puestos se invierten si atendemos a NR o a NMI; ello se debe a que en realidad el NR de cada especie (sobre el que se han establecido los cálculos), no es muy alto, por lo que podemos decir que nos encontramos en realidad ante cifras comparables.

El resto de las especies representadas en las muestras, alcanzan cifras pequeñas, pero su presencia y proporciones es la habitual en este tipo de yacimientos (etapa cultural); pero habría que destacar la existencia de especies como Capra pyrenaica y Capreolus capreolus, así como la ausencia de Canis familiaris.

La suma total de especies no domésticas nos hace pensar en una cierta importancia de la caza en el conjunto de las actividades humanas; si bien este número de especies silvestres es notablemente inferior al de domésticas.

Podría conjeturarse otra posible actividad humana, como es el trabajo o simple utilización de la piel, a juzgar por el corte intencionado que puede apreciar- se en un astrágalo de Bos taurus asignado al Nivel II; en él se aprecia un corte diagonal cuya intención es eliminar la pezuña del animal.

La proporción aparentemente elevada de o entre los restos de Bos taurus en el nivel II (falanges), no es significativa por el escaso número de restos.

La pequeña representación de la porción axial en la generalidad de la muestra, puede deberse, como ya se comenta en el correspondiente apartado previo, a la selección de los restos; encontrándonos así ante una discrepancia con respecto a los datos teóricos, como la que podemos apreciar por ejemplo en el caso de los bóvidos del Nivel II:

$\begin{array}{lcc}\text { Porción } & \text { P. Teórica } & \text { P. Nivel II } \\ \text { craneal } & 18 \% & 40 \% \\ \text { axial } & 43 \% & 2 \% \\ \text { apendicular } & 39 \% & 57 \%\end{array}$

En cuanto a moluscos se refiere, estos constituyen una fracción marginal de los restos faunísticos recuperados en este yacimiento, frecuencia posiblemente determinada por su propia función de aprovechamiento; desde luego en ningún caso de carácter alimentario.

\section{BIBLIOGRAFÍA}

GRAYSON, D.K., 1984: «Quantitative Zooarchaeology». Acad. Press Orlando.

GONZÁLEZ PRATS, A., 1983: «El yacimiento arqueológico de Peña Negra (Crevillente, Alicante)». Rev. de Arqueología, 28.

GONZÁLEZ PRATS, A., 1990: Nueva luz sobre la protohistoria del sudeste. Alicante.

MIGUEL, F.J. y MORALES, A., 1983: «Catálogo para la unificación de las medidas del esqueleto postcraneal de los mamíferos

en Españas. Primeras Jornadas de Metodología de Investigación Prehistórica. Soria.

MIGUEL, F.J. y MORALES, A., 1983: «Informe sobre los restos faunísticos recuperados en el yacimiento del Cerro de Santa Ana (Entrena, Logroño)». Berceo (Ciencias), 1, 49-165.

SCHMID, E., 1972: Tierknochenatlas. Atlas of animal bones. Londres. 